\title{
Long term response with abiraterone without lhrh analogs in metastatic castration resistant prostate cancer
}

Dellavedova Tristan*, Malizia Reynoso Enzo, Quinteros Leandro, Nobile Raul, Ponzano Rolando, Sarria Juan Pablo, Olmedo Jose and Minuzzi Federico

FUCDIM, Cordoba, Argentina

\begin{abstract}
Main findings: A clinically localized Gleason score 6 adenocarcinoma was diagnosed to a 59 year-old man, surgically treated with succesful oncologic outcomes. However, disease progression led to a diagnosis of metastatic castration resistant prostate cancer (mCRPC) 11 years later, treated with Abiraterone with a prostatespecific antigen (PSA) response of 32 months.

The particular characteristic of this case is that Abiraterone was used without luteinizing hormone releasing hormone (LHRH) analogs and the clinical and biochemical response was prolonged.
\end{abstract}

\begin{abstract}
Abbreviations: CRPC: Castration Resistant Prostate Cancer; mCRPC: metastatic Castration Resistant Prostate Cancer; PSA: Prostate-specific Antigen; LHRH: Luteinizing Hormone Releasing Hormone; LH: Luteinizing Hormone; ADT: Androgen Deprivation Therapy; CYP 17: Enzyme 17a- Hidroxilase/C17,20-Liase; ASCO: American Society of Clinical Oncology
\end{abstract}

\section{Case hypothesis}

Abiraterone blocks cytochrome P450 c17, thereby inhibiting androgen synthesis by the adrenal glands, testes and within the prostate tumor [1-4].

Two studies led to the approval of Abiraterone, COU AA 301 showed prolonged survival after docetaxel treatment [5] and COU AA 302, in chemotherapy-naive patients [6]. In both, Abiraterone was associated with LHRH agonists, setting the standard for its use together.

The rationale for this association is that luteinizing hormone (LH) must be blocked because fall of testosterone would cause a rise in $\mathrm{LH}$ production, with a testosterone increase and a flare effect [7]. However, such effect has not been seen in castrated patients [8].

\section{Promising future implications}

The use of Abiraterone alone, with succesful outcomes in managing mCRPC supports an important line of research that is already being investigated in clinical trials $[9,10]$ and might eventually change the current state of the art for mCRPC.

\section{Scenario}

A 59-year old patient with a prostate-specific antigen (PSA) value of $12 \mathrm{ng} / \mathrm{ml}$, was diagnosed in 2002 with a localized, intermediate-risk prostate cancer according to $\mathrm{D}^{\prime}$ Amico risk stratification [11]. He was treated with radical prostatectomy and standard lymphadenectomy, with organ-confined disease at final pathology and a 5-year complete response without evidence of disease recurrence. However, in 2007 PSA rose, androgen deprivation therapy (ADT) was initiated, bone metastases appeared, metastatic disease was controlled for more than 3 years including secondary hormonal manipulations (antiandrogen withdrawal, use of LHRH antagonists) and finally metastatic castration resistant prostate cancer (mCRPC) was diagnosed in 2013 and treated with Abiraterone. Right hip was irradiated due to symptomatic bone metastasis. Osteonecrosis of the jaw developed related to the use of zoledronic acid and was succesfully treated, and a 32-month PSA response to Abiraterone was reported, associated with Prednisone but without the use of concomitant luteinizing hormone releasing hormone (LHRH) agonists. This occurred because the patients' medical insurance company did not accept the prescription of Abiraterone and LHRH analogs together. The treatment was well tolerated by the patient, who already had renal insuficiency and heart failure. PSA values were below $1 \mathrm{ng} / \mathrm{ml}$ for 2 years and started to rise afterwards, reaching $12 \mathrm{ng} / \mathrm{ml}$ in March 2016, surpassing the value of PSA when Abiraterone treatment was initiated $(8 \mathrm{ng} / \mathrm{ml})$. While the patient being treated, neither urinary complaints nor metastases-related symptoms developed.

The patient is currently undergoing re-staging imaging studies and was sent to Clinical Oncology Department for furher treatment.

\section{Case hypothesis and rational}

Prostate cancer is an androgen-dependent disease that generally responds to surgical or medical castration, however, after a variable period of time, cancer is reactivated in certain cases despite castration levels of testosterone, shifting to the stage of CRPC [12]. Progression to this final stage is still driven by androgens, involving different mechanisms of resistance. Among these pathways is the up-regulation of androgen biosynthesis enzymes, producing an increase in intratumoral androgen concentrations [13-15].

Correspondence to: Dellavedova Tristan, Urologic Oncology Department, FUCDIM, Cordoba, Argentina, E-mail: trisdellavedova@hotmail.com

Received: April 22, 2017; Accepted: May 19, 2017; Published: May 22, 2017 
Abiraterone is an androgen-biosynthesis inhibitor, selectively blocking the enzyme 17a- hidroxilase/C17,20-liase (CYP17), a critical enzyme in testosterone synthesis, necessary for androgen synthesis in testicular, adrenal and prostatic tumour tissue, since it favours the conversion of pregnenolone and progesterone to dehydroepiandrosterone and androstenedione [16].

The current state of the art for managing metastatic CRPC indicates that Abiraterone must be given together with LHRH agonists [1719 ], since this is how the drug was used in clinical trials that led to its approval $[5,6]$.

The rationale for this association is that after LHRH agonist administration, LH peaks at about three times the baseline level at 24 hours. Testosterone rise is delayed, with a peak reached at approximately day 3 , falling to pretreatment levels by day 7 . Ultimately, castrate levels are achieved by 3 weeks following initiation of therapy. Blockade of clinical flare can be accomplished with different agents such as Cyproterone, Diethylstilbestrol, Flutamide, or Nilutamide [7]. Although not often used, treatment with Ketoconazole will also prevent flare [20].

Ketoconazole, an imidazole antifungal agent, inhibits many cytochrome $P 450$ enzymes including CYP17A1, suppressing adrenal and intratumoral steroidogenesis by inhibiting the conversion of cholesterol to pregnenolone. It has been used after ADT failure for more than 30 years with PSA response rates and time to progression of $20-75 \%$ and 3-10 months, respectively. A study published in 2014, compared Ketoconazole with Abiraterone in post Docetaxel mCRPC. PSA response, progression free survival, radiological PFS, overall survival and treatment interruption due to severe adverse events were analyzed. In all the parameters compared Abiraterone was superior, with less toxicity [21].

This analysis brings the issue of the real need of LHRH analogs together with Abiraterone. If Ketoconazole has been used to avoid the flare, and Abiraterone is superior to Ketoconazole, isn't it enough to use Abiraterone monotherapy?

In the case presented Abiraterone was administered with Prednisone but without associated LHRH analogs. There are very few reports about the use of Abiraterone without LHRH analogs, anyway, it seems to maintain efficacy [8].

Two clinical trials evaluating Abiraterone monotherapy are ongoing. One of them is a phase 2, randomized, 3-arm study of Abiraterone alone, Abiraterone plus Degarelix, and Degarelix alone for patients with prostate cancer with a rising PSA or a rising PSA and nodal disease following radical prostatectomy. The primary outcomes are progression-free survival and soft tissue (lymph nodes) complete response. This interventional study is sponsored by Memorial Sloan Kettering Cancer Center and is still recruiting patients [9].

The second study is SPARE trial. It is a phase 2 multicenter, randomized, open-label study with two arms, Abiraterone plus Prednisone plus LHRH-therapy versus Abiraterone plus Prednisone. The primary outcome is radiographic-progression-free survival. It is a German study, some sites are still recruiting and others already closed [10].

Besides maintaining efficacy, Abiraterone monotherapy spares the patient a series of well-known adverse events related to ADT use: cardiovascular morbidity, metabolic syndrome, fatigue, sarcopenia and muscular weakness, altered body composition, osteoporosis and bone fractures, arterial stiffness, cognitive decline, loss of libido and sexual disfunction [22].

American Society of Clinical Oncology (ASCO) published in 2014 recomendations on systemic therapies for metastatic CRPC patients, based on clinical benefit, harm, evidence strenght and recommendation strenght. This document, regarding continuous ADT, states that it should be continued indefinitely regardless of additional therapies. However, it is recognized that clinical benefit is moderate, harm is moderate, evidence strength is weak and recommendation strength is moderate. They declare that in incurable metastatic prostate cancer patients, the goal of treatment is to provide the best possible quality of life. In this age group, additional chronic conditions are common, adding complexity to the management of these patients. Among these more frequent diseases are hypertension, hyperlipidemia, diabetes, ischemic heart disease, anemia, depression, heart failure, arthritis, chronic obstructive pulmonary disease and chronic kidney disease [23]. ADT has a direct negative impact on most of these diseases affecting prostate cancer patients [12].

Our reported 32-month response was only achieved by few of the patients in the COU AA 302 trial and none of the COU AA 301, the pivotal trials that led to Abiraterone approval $[5,6]$. In fact, the longer response reported in these studies was 34,9 months (maximun rank of response to treatment in an interim analysis of the COU AA 302 published in 2014) [24] and these results were obtained with associated LHRH analogs use.

The outcomes presented in this case report and the cited ongoing trials present a situation that was not thought a few years ago. If confirmed by further scientific evidence, not using a LHRH analog in this clinical scenario would diminish toxicity as well as costs of treatment, maintaining good oncologic outcomes.

\section{Discussion and future perspectives}

Available evidence has set the standard of care for mCRPC associating Abiraterone and LHRH analogs [17-19].

However, recent publications are challenging this gold-standard and Abiraterone is being used in clinical trials and few case reports, without LHRH agonists [8-10] and it seems that the effect of the drug is enough to maintain androgen blockade and allowing disease control, without compromising patient's oncologic status and general health. Besides, studies prove that Abiraterone is superior to Ketoconazole [21], and the latter has historically been used to avoid testosterone flare [20].

Even more, the withdrawal of LHRH analogs would spare the patients many drug related drawbacks and lower the costs of treatment.

Some questions arise: are LHRH agonists always necessary for mCRPC patients treated with Abiraterone? Could this monotherapy maintain its efficacy at long term? Might it be possible to challenge the state of the art for treating mCRPC patients?

Results of ongoing trials are expected, as well as more scientific evidence, but it looks like Abiraterone monotherapy treatment is here to stay.

\section{References}

1. Potter GA, Barrie SE, Jarman M, Rowlands MG (1995) Novel steroidal inhibitors of human cytochrome P45017 alpha (17 alpha-hydroxylase-C17,20-lyase): potential agents for the treatment of prostatic cancer. J Med Chem 38: 2463-2471. [Crossref]

2. Attard G, Belldegrun AS, de Bono JS (2005) Selective blockade of androgenic steroid synthesis by novel lyase inhibitors as a therapeutic strategy for treating metastatic prostate cancer. BJU Int 96: 1241-6. [Crossref] 
3. Barrie SE, Haynes BP, Potter GA, Chan FC, Goddard PM, et al. (1997) Biochemistry and pharmacokinetics of potent non-steroidal cytochrome P450(17alpha) inhibitors. $J$ Steroid Biochem Mol Biol 60: 347-351. [Crossref]

4. Jarman M, Barrie SE, Llera JM (1998) The 16,17-double bond is needed for irreversible inhibition of human cytochrome p45017alpha by abiraterone (17-(3-pyridyl) androsta-5, 16-dien-3beta-ol) and related steroidal inhibitors. J Med Chem 41: 53755381. [Crossref]

5. de Bono JS, Logothetis CJ, Molina A, Fizazi K, North S, et al. (2011) Abiraterone and increased survival in metastatic prostate cancer. N Engl J Med 364: 1995-2005. [Crossref]

6. Ryan CJ, Smith MR, de Bono JS, Molina A, Logothetis CL, de Souza P, et al. (2013) Abiraterone in metastatic prostate cancer without previous chemotherapy. $N$ Engl J Med 368: 138-48. [Crossref]

7. Thompson IM (2001) Flare Associated with LHRH-Agonist Therapy. Rev Urol 3: S1014. [Crossref]

8. Barreiro DM, Castro Montiel F, Parise ML, Rivero OA, Rovetto S, et al. (2015) Abiraterone alone. Rev Arg Urol 80: 82-86.

9. 3-arm study of abiraterone acetate alone, abiraterone acetate plus degarelix, a GnRH antagonist, and degarelix alone for patients with prostate cancer with a rising PSA or a rising PSA and nodal disease following definitive radical prostatectomy. ClinicalTrials. gov. Identifier: NCT01751451

10. Trial of abiraterone acetate plus LHRH-therapy versus abiraterone acetate sparing LHRH-therapy in patients with progressive chemotherapy-naive castration-resistant prostate cancer (SPARE). ClinicalTrials.gov. Identifier: NCT02077634.

11. D'Amico AV, Whittington R, Malkowicz SB, Schultz D, Blank K, et al. (1998) Biochemical outcome after radical prostatectomy, external beam radiation therapy, or interstitial radiation therapy for clinically localized prostate cancer. JAMA 280: 969974. [Crossref]

12. Dellavedova T, Boetto M, Olmedo J, Sarria JP, Nóbile R, et al. (2016) Enzalutamide as monotherapy for advanced prostate cancer: why not? Arch Esp Urol 69: 393-397. [Crossref]

13. Holzbeierlein J, Lal P, LaTulippe E, Smith A, Satagopan J, Zhang L, et al. (2004) Gene expression analysis of human prostate carcinoma during hormonal therapy identifies androgen-responsive genes and mechanisms of therapy resistance. Am J Pathol 164: 217-27. [Crossref]
14. Stanbrough M, Bubley GJ, Ross K, Golub TR, Rubin MA, et al. (2006) Increased expression of genes converting adrenal androgens to testosterone in androgenindependent prostate cancer. Cancer Res 66: 2815-25. [Crossref]

15. Montgomery RB, Mostaghel EA, Vessella R, Hess DL, Kalhorn TF, et al. (2008) Maintenance of intratumoral androgens in metastatic prostate cancer: a mechanism for castration-resistant tumor growth. Cancer Res 68: 447-54. [Crossref]

16. European Medicines Agency (EMA). Abiraterone Acetate. Anex I. Technical file with product characteristics. Consulted in http://www.ema.europa.eu/ema/ index.jsp?curl=pages/medicines/human/medicines/002321/human_med_001499. jsp\&mid=WC0b01ac058001d124 on March, 17th, 2016.

17. Heidenreich A, Bastian PJ, Bellmunt J, Bolla M, Joniau S, et al. (2014) EAU Guideline on Prostate Cancer. Part II: Treatment of Advanced, Relapsing, and Castration-Resistant Prostate Cancer. Eur Urol 65: 467-79. [Crossref]

18. Cookson MS, Roth BJ, Dahm P, Engstrom C, Freedland SJ, et al. (2013) Castrationresistant prostate cancer: AUA Guideline. J Urol 190: 429-438. [Crossref]

19. Mohler JL, Armstrong AJ, Bahnson RR, Cohen M, D'Amico AV, et al. (2016) National Comprehensive Cancer Network (NCCN) Clinical Practice Guidelines in Oncology. Prostate Cancer.

20. Allen JM, Kerie DJ, Ware H (1983) Combined treatment with ketoconazole and luteinizing hormone- releasing hormone analogue: a novel approach to resistant progressive prostatic cancer. Br Med J 287: 1766. [Crossref]

21. Peer A, Gottfried M, Sinibaldi V, Carducci MA, Eisenberger MA, et al. (2014) Comparison of Abiraterone Acetate Versus Ketoconazole in Patients with Metastatic Castration Resistant Prostate Cancer Refractory to Docetaxel. Prostate 74: 433-440. [Crossref]

22. Merseburger A (2016) Do we need to continue androgen deprivation therapy? March 2015. Consulted in Uroweb, of European Association of Urology, in uroweb.org/dowe-need-to-continue-androgen-deprivation-therapy on March, 16th, 2016.

23. Basch E, Loblaw DA, Oliver TK, Carducci M, Chen RC, et al. (2014) Systemic Therapy in Men With Metastatic Castration-Resistant Prostate Cancer: American Society of Clinical Oncology and Cancer Care Ontario Clinical Practice Guideline. $J$ Clin Oncol 32: 1-17. [Crossref]

24. Rathkopf DE, Smith MR, de Bono JS, Logothetis CJ, Shore ND, et al. (2014) Updated Interim Efficacy Analysis and Long-term Safety of Abiraterone Acetate in Metastatic Castration-resistant Prostate Cancer Patients Without Prior Chemotherapy (COUAA-302). Eur Urol 66: 815-825. [Crossref]

Copyright: (C2017 Tristan D. This is an open-access article distributed under the terms of the Creative Commons Attribution License, which permits unrestricted use, distribution, and reproduction in any medium, provided the original author and source are credited. 